\title{
Antinociceptive and Anti-Inflammatory Effects of Bixin, a Carotenoid Extracted from the Seeds of Bixa orellana
}

Authors

Samanta Daliana Golin Pacheco ${ }^{1 *}$, Alexia Thamara Gasparin ${ }^{2 *}$, Carlos Henrique Alves Jesus ${ }^{2}$, Bruna Bittencourt Sotomaior ${ }^{2}$, Ana Clara Sans Salomão Brunow Ventura², Daiany Darlly Belo Redivo², Daniela de Almeida Cabrini ${ }^{2}$, Josiane de Fátima Gaspari Dias ${ }^{1}$, Marilis Dallarmi Miguel ${ }^{1}$, Obdulio Gomes Miguel ${ }^{1}$, Joice Maria da Cunha ${ }^{2}$

Affiliations

1 Postgraduate Program in Pharmaceutical Sciences, Federal University of Paraná, Curitiba, Parana, Brazil

2 Laboratory of Pharmacology of Pain, Department of Pharmacology, Federal University of Paraná, Curitiba, Parana, Brazil

Key words

Bixa orellana, Bixaceae, inflammation, nociception, myeloperoxidase, carrageenan

received July 1,2019

revised August 30, 2019

accepted September 4, 2019

Bibliography

DOI https://doi.org/10.1055/a-1008-1238

Published online September 23, 2019 | Planta Med 2019; 85:

1216-1224 @ Georg Thieme Verlag KG Stuttgart · New York | ISSN 0032-0943

Correspondence

Prof. Dr. Joice Maria da Cunha

Department of Pharmacology, Biological Sciences Building, Federal University of Parana

R. Coronel Francisco H dos Santos S/N, P. O. Box 19031, 81531-980 Curitiba, Paraná, Brazil

Phone: + 554133611720 , Fax: + 554132662042

joice.cunha@ufpr.br

Supporting information available online at

http://www.thieme-connect.de/products

\section{ABSTRACT}

Bixin is the main natural apocarotenoid extracted from the seeds of Bixa orellana, widely used as a cosmetic and textile colorant. Despite the description of several pharmacological properties of $B$. orellana extracts, little has been studied regarding the pharmacological properties of bixin. Then we aimed to investigate the potential anti-inflammatory and antinociceptive effect of bixin in preclinical models of inflammation and acute pain. The anti-inflammatory activity of bixin (15 or $30 \mathrm{mg} / \mathrm{kg}$, orally) was determined using carrageenaninduced paw edema and the myeloperoxidase (MPO) activity in male Wistar rats. The antinociceptive effect of bixin was assessed in the formalin and hot plate tests in rats (at same doses) and in the acetic acid-induced writhing test in Swiss albino male mice (at doses of 27 or $53 \mathrm{mg} / \mathrm{kg}$ ). General locomotor activity was evaluated in the open field test. Only the higher dose of bixin significantly decreased the carrageenaninduced paw edema and the MPO activity and increased the latency time in the hot plate. Both doses of bixin significantly reduced the number of flinches in both phases of the formalin test and the number of acetic acid-induced writhings without changing the locomotor performance in the open field test. This study validates the use of bixin as an anti-inflammatory trough mechanism related to the reduction of neutrophil migration. Furthermore, this is the first report showing the antinociceptive property of bixin, which does not appear to be related to the sedative effect. Further studies are necessary to characterize the mechanisms involved in these effects.

\section{Introduction}

Bixin ( $\bullet$ Fig. 1) is a major liposoluble diapocarotenoid extracted from the seeds of Bixa orellana Linné (Bixaceae). Among the natural carotenoids, bixin stands out chemically for presenting the cis conformation, unusual among the carotenoids, and for presenting a carboxylic group and a methyl ester in its chemical structure, which confers fat solubility to the molecule $[1,2]$. Bixin is widely used as an FDA-approved food colorant and additive, as well as a cosmetic and textile colorant. It is considered the main pigment of the seeds of annatto, the common name of the species $B$. orellana, being the greater responsible for conferring the reddish-orange tonality, characteristic of seeds [3,4]. Among the several plants that have these compounds and high colorant potential, annatto is one of the most economically important plants [5].

* Samanta Daliana Golin Pacheco and Alexia Thamara Gasparin made equal contributions to this study. 
In Mexico and South America, B. orellana has been traditionally used to treat infectious and inflammatory diseases of the skin, prostate, gastrointestinal tract, and chest pain [6]. In fact, several in vitro or in vivo studies have already demonstrated varied biological properties of $B$. orellana extracts or fractions, such as antibacterial, antifungal, antioxidant, and antimalarial [1]. Importantly for this study, Benoit et al., (1976) [7] described a significant reduction of carrageenan-induced paw edema in rats after treatment with ethanolic extract of $B$. orellana. Additionally, treatment with crude aqueous extract of $B$. orellana leaves exhibited significant inhibitory activity against bradykinin-induced inflammation [8]. Considering the nociception, preliminary data obtained by Shilpi et al. (2006) [9] have already demonstrated that methanol extract of $B$. orellana leaves significantly and dose-dependently reduced the acetic acid-induced writhing response in mice.

Although bixin is the main carotenoid of $B$. orellana and that carotenoids are known compounds with several pharmacological properties $[10,11]$, few studies evaluate the effects of isolated bixin. It has been already shown its protective effect on cells and tissues with antioxidant, antimyeloma, antigenotoxicity, and anticlastogenicity actions, being considered a biological neutralizer of reactive oxygen species [12]. In addition, studies have demonstrated the anti-inflammatory activity of bixin through the antioxidant transcription factor Nrf2 activation [4, 13], and its efficiency in accelerating wound healing as well as reducing the scar tissue area [14]. Although pain is one of the cardinal signs of inflammation, to our knowledge there are no studies evaluating the antinociceptive potential of bixin. Thus, besides validating its anti-inflammatory action, this study aimed to evaluate antinociceptive activities of bixin in murine models of inflammatory pain.

\section{Results}

The Fig. 2 (panel A) shows the effect of oral treatment with bixin (at doses of 15 or $30 \mathrm{mg} / \mathrm{kg}$ ) or vehicle (corn oil) on carrageenan $(\mathrm{Cg})$ induced edema in rats. Two-way analysis of variance (ANOVA) showed a significant effect on experimental groups $\left[F_{(4,35)}=16.74 ; p<0.05\right]$ and time $\left[F_{(4,140)}=146.0 ; p<0.05\right]$, besides an interaction between these 2 factors $\left[F_{(16,140)}=8.669\right.$; $\mathrm{p}<0.05]$. The post hoc test of Bonferroni showed a significant difference between all groups that received $\mathrm{Cg}$ when compared with the vehicle $(\mathrm{VEH})$ /saline $(\mathrm{SAL})$-treated group $(\mathrm{p}<0.05)$, demonstrating the $\mathrm{Cg}$-induced increase in paw edema when compared to the SAL group peaking 2 and $3 \mathrm{~h}$ after $\mathrm{Cg}$ injection. Besides, the Bonferroni's test showed that the treatment with bixin $(30 \mathrm{mg} / \mathrm{kg})$ significantly attenuated the paw edema at first and second hour after $\mathrm{Cg}$ injection $(\mathrm{p}<0.05)$. The paw edema in dexamethasone/Cg-treated group was significantly different in comparison with vehicle/Cg-treated group, 2, 3, and $4 \mathrm{~h}$ after $\mathrm{Cg}$ injection $(p<0.05)$.

Analyzing the area under the curve (AUC) of total edema during the $4 \mathrm{~h}$ after $\mathrm{Cg}$ treatment ( $\triangleright$ Fig. 2, panel B), 1-way ANOVA showed a significant effect on experimental groups $\left[F_{(4,35)}=\right.$ 15.87; $p<0.05]$. The post hoc test of Bonferroni showed that all experimental groups treated with $\mathrm{Cg}$ were significantly different when compared to the saline-treated group $(p<0.05)$. Additionally, this test demonstrated that the experimental groups treated

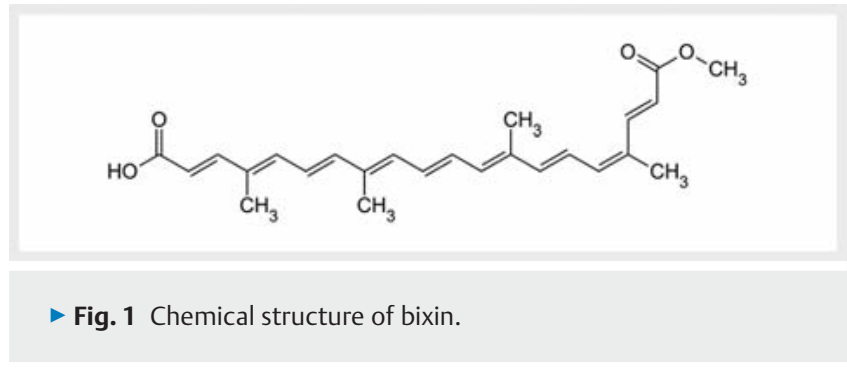

with bixin (dose of $30 \mathrm{mg} / \mathrm{kg}$ ) or dexamethasone were statistically different from the vehicle/Cg-treated group $(p<0.05)$, but not different from each other $(p>0.05)$.

- Fig. 3 shows the effect of oral treatment with bixin (at doses of 15 or $30 \mathrm{mg} / \mathrm{kg}$ ) or vehicle (corn oil) on the myeloperoxidase (MPO) activity. One-way ANOVA showed a significant effect on experimental groups $\left[F_{(4,30)}=14.92 ; p<0.05\right]$. The post hoc test of Bonferroni showed a significant difference between all groups that received $\mathrm{Cg}$ injection in comparison to the VEH/SAL-treated group ( $p<0.05$ ). Therefore, the injection of $\mathrm{Cg}$ causes an increase in MPO activity compared to the SAL group. Besides, the Bonferroni's test showed a significant difference between bixin $/ \mathrm{Cg}$, at a dose of $30 \mathrm{mg} / \mathrm{kg}$, and dexamethasone/Cg-treated groups, in comparison to the vehicle/ $\mathrm{Cg}$-treated group $(\mathrm{p}<0.05)$. Thus, the treatment with bixin, at the dose of $30 \mathrm{mg} / \mathrm{kg}$ or with dexamethasone was able to significantly reduce the MPO activity in comparison to the $\mathrm{VEH} / \mathrm{Cg}$ group $(\mathrm{p}<0.05)$. No significant difference was observed between the bixin $(30 \mathrm{mg} / \mathrm{kg})$ and dexamethasone $/ \mathrm{Cg}$ treated groups $(p>0.05)$.

The Fig. 4 (panel A) demonstrates the cumulative number of paw flinches induced by formalin injection in rats treated with bixin (at doses of 15 or $30 \mathrm{mg} / \mathrm{kg}$ ) or vehicle (corn oil). Two-way ANOVA with repeated measures showed a significant effect on experimental groups $\left[F_{(2,21)}=99.37 ; p<0.05\right]$ and time $\left[F_{(11,231)}=\right.$ 314.4; $p<0.05]$, besides an interaction between these factors $\left[F_{(22,231)}=28.28 ; p<0.05\right]$. The post hoc test of Bonferroni showed a significant difference between bixin (at doses of 15 and $30 \mathrm{mg} / \mathrm{kg}$ ) and VEH-treated group at all time points analyzed after formalin injection ( $p<0.05)$.

Analyzing the total paw flinches response during the formalin test ( $\bullet$ Fig. 4, panel B), 1-way ANOVA showed a significant effect on experimental groups during the phase I $\left[F_{(2,21)}=54.46\right.$; $\mathrm{p}<0.05]$ and phase II $\left[\mathrm{F}_{(2,21)}=28.41 ; \mathrm{p}<0.05\right]$, but not during the quiescent interphase $\left[F_{(2,21)}=3.258 ; p>0.05\right]$. The post hoc test of Bonferroni showed that the bixin (at doses of 15 and $30 \mathrm{mg} / \mathrm{kg}$ ) induces a significant decrease of formalin-induced flinches compared to the VEH-treated group $(p<0.05)$ during phases I and II of the formalin test, but not during the quiescent interphase. No significant differences were observed between the doses of bixin during phase I $(p>0.05)$. However, the number of flinches inhibited by the doses of bixin were significantly different during phase II of the formalin test $(p<0.05)$.

The Fig. 5 (panel A and B) demonstrates the number of writhings induced by acid acetic in mice treated with bixin (at doses of 27 or $53 \mathrm{mg} / \mathrm{kg}$ ) or vehicle (VEH; corn oil). Analyzing the time course of acetic acid-induced writhings ( $\vee$ Fig. 5, panel A), 

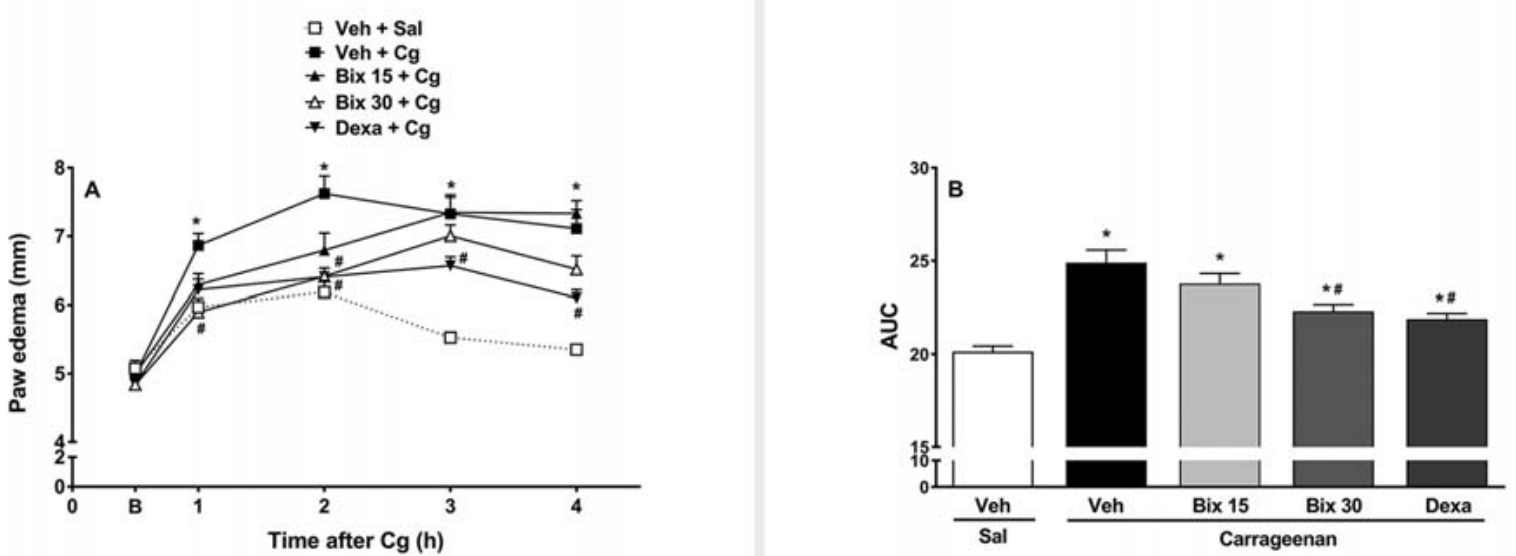

- Fig. 2 Effect of bixin or dexamethasone on carrageenan-induced paw edema in rats. Vehicle (Veh; corn oil; $1 \mathrm{~mL} / \mathrm{kg}$, p. o.), bixin (Bix; 15 or $30 \mathrm{mg} / \mathrm{kg}$, p. o.), or dexamethasone (Dexa; $1 \mathrm{mg} / \mathrm{kg}$, s. c.) was administered $1 \mathrm{~h}$ before carrageenan (Cg; $200 \mu \mathrm{g} / \mathrm{paw}$ in $0.1 \mathrm{~mL}$ of saline) treatment. Control group received Veh (equivalent volume) followed by intra-plantar injection of saline (Sal; $0.1 \mathrm{~mL} / \mathrm{paw})$. Panel A shows the paw thickness (in $\mathrm{mm}$ ) measured before (B) and 1, 2, 3, and $4 \mathrm{~h}$ after $\mathrm{Cg}$ or Sal injection. Panel B shows the area under curve (AUC) in arbitrary units (AU) of total edema during the $4 \mathrm{~h}$. The data represent mean $+\operatorname{SEM}(n=8) .{ }^{*} \mathrm{p}<0.05$ compared to Veh + Sal-treated group. \# $p<0.05$ compared to Veh + Cg-treated group.

2-way ANOVA showed a significant effect on experimental groups $\left[F_{(2,28)}=31.87 ; p<0.05\right]$ and time $\left[F_{(5,140)}=375.9 ; p<0.05\right]$, besides an interaction between these factors $\left[F_{(10,140)}=17\right.$; $\mathrm{p}<0.05]$. The Bonferroni post hoc analysis showed a significant difference between bixin (at doses of 27 and $53 \mathrm{mg} / \mathrm{kg}$ ) and vehicle-treated group at 10,15, 20, 25, and 30 min after acid acetic injection $(p<0.05)$.

When analyzed the total writhing response (panel B), 1-way ANOVA showed the effect of the experimental groups $\left[F_{(2,28)}=\right.$ 31.31; $p<0.05$ ] factor. The post hoc test of Bonferroni showed that bixin treatment at both tested doses significantly reduced the number of acetic acid-induced writhings when compared to the VEH-treated group $(p<0.05)$. Furthermore, the bixin doses also differ statistically from each other $(p<0.05)$.

The Fig. 6 (panel A) demonstrates the effect of bixin (at doses of 15 or $30 \mathrm{mg} / \mathrm{kg}$ ) or vehicle (VEH; corn oil) on the latency time in the hot plate apparatus. One-way ANOVA showed a significant effect of the experimental groups $\left[F_{(2,37)}=4.061 ; p<0.05\right]$ factor. The post hoc test of Bonferroni showed that bixin treatment (only at a dose of $30 \mathrm{mg} / \mathrm{kg}$ ) induced a significant increase in the latency time compared to the vehicle-treated group $(p<0.05)$.

- Fig. 6 (panel B) shows the effect of bixin treatment (at doses of 15 or $30 \mathrm{mg} / \mathrm{kg}$ ) or vehicle (VEH; corn oil) on the number of crossings at the open field apparatus. One-way ANOVA show no significant effect on experimental groups $\left[F_{(2,16)}=0.3298\right.$; $p>0.05]$.

\section{Discussion}

In the current study, the anti-inflammatory potential of bixin was validated using preclinical models of acute inflammation. First, we demonstrated that oral treatment with bixin was able to prevent

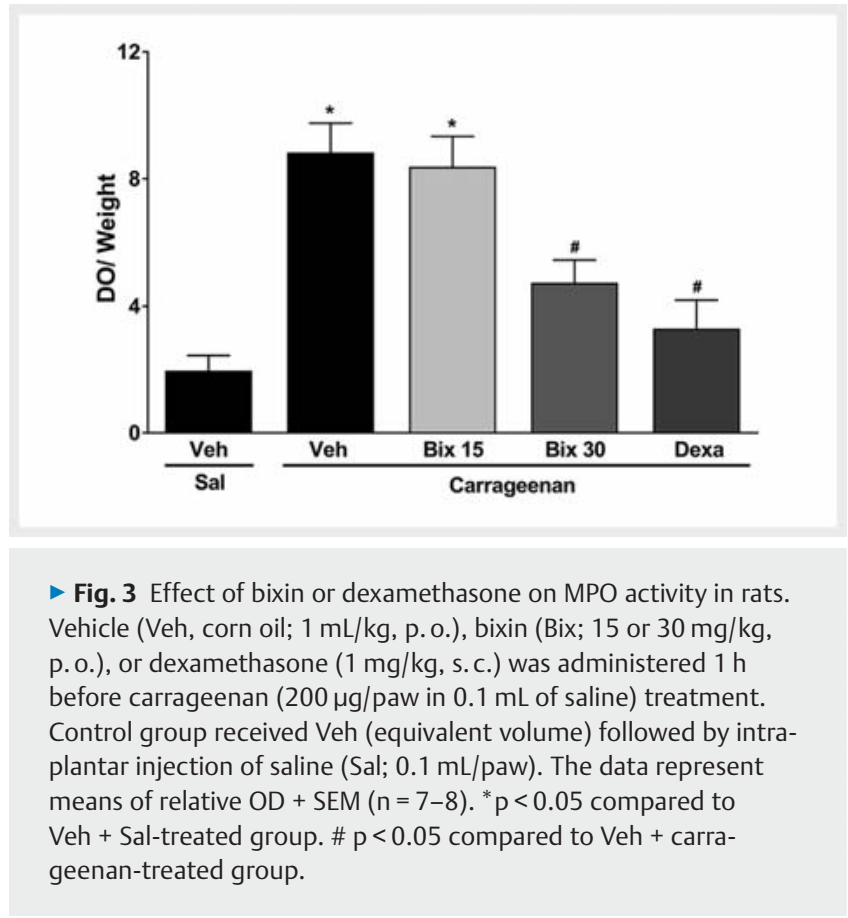

the development of carrageenan-induced paw edema in rats, which seems to be related to the inhibition of neutrophil migration to the inflammation site. Besides, we observed, to our knowledge, for the first time in the literature, the antinociceptive effect of acute treatment with bixin using preclinical models of thermal and chemical nociception in rats and mice. This effect does not seem to be associated with sedative effects since the bixin treatment did not change the locomotor performance in the open field test. Additionally, the ability of bixin to attenuate nociceptive re- 


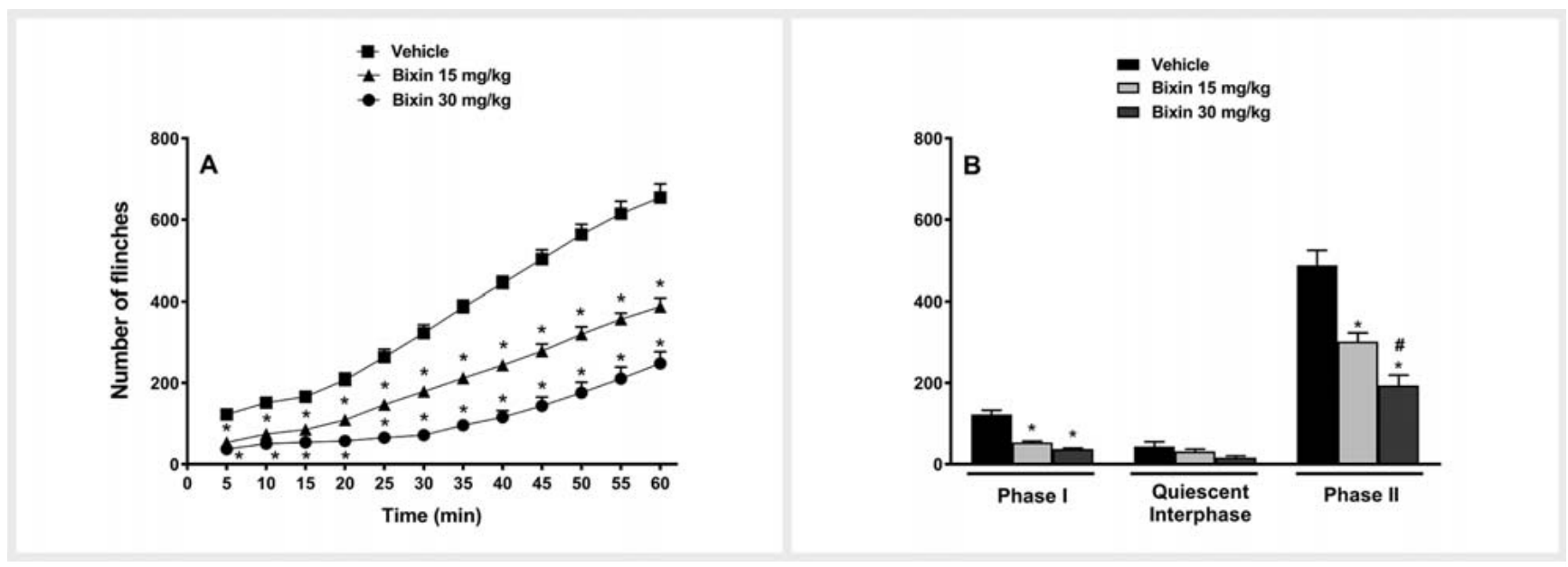

- Fig. 4 Effect of bixin in formalin-induced nociception in rats. Vehicle (corn oil; $1 \mathrm{~mL} / \mathrm{kg}$, p. o.) or bixin (Bix; 15 or $30 \mathrm{mg} / \mathrm{kg}$, p. o.) was administered $1 \mathrm{~h}$ before formalin $(2.5 \% ; 50 \mu \mathrm{L} / \mathrm{rat}$ ). Panel A shows the number of formalin-induced cumulatively counted flinches for $60 \mathrm{~min}$, divided in $5 \mathrm{~min}$ counts. Panel B shows the total number of flinches exhibited during the first phase (phase I: $0-5$ min), quiescent interphase (6-15 min) and the second phase (phase II: $15-60 \mathrm{~min}$ ) of formalin test. The data represent mean + SEM ( $n=7-9)$. ${ }^{*}<0.05$ compared to vehicle-treated group. \# $\mathrm{p}<0.05$ when compared to bixin-treated group $(15 \mathrm{mg} / \mathrm{kg})$.

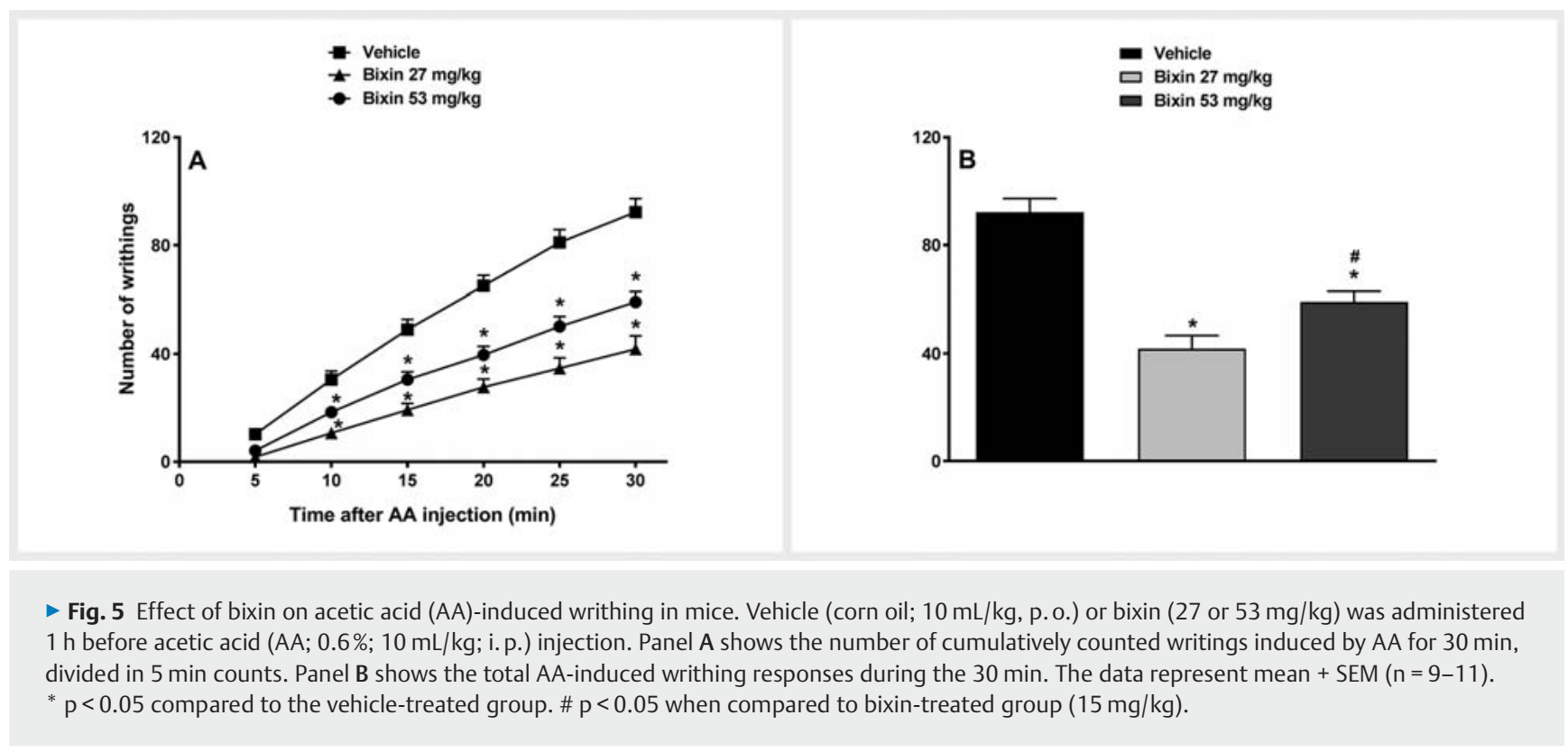

sponses induced by multiple stimuli (chemical and thermal) suggests possible participation of the molecule in peripheral and central anti-nociceptive mechanisms. This broad distribution of bixin is corroborated by previous findings in the literature which indicate that as a nonpolar substance, bixin reaches the systemic circulation (and therefore is detectable in plasma) $1 \mathrm{~h}$ later after oral administration in an oily vehicle $[15,16]$.

Interestingly, previous studies have already demonstrated that $B$. orellana extracts or fractions significantly attenuate the inflammatory response induced by diverse stimuli $[8,9]$. When considering studies with isolated bixin, few in vivo and in vitro studies have also demonstrated the ability of bixin to reduce inflammation [13,
$17,18]$. In our study, oral treatment with bixin promotes a significant reduction of paw edema in the first and second hour after administration of carrageenan. As previously described, paw edema induced by carrageenan produces a biphasic response [19] wherein the first phase (ranging from 0 to 60 min after administration of carrageenan) is characterized by the release of substances such as histamine, serotonin and bradykinin while the second phase (from 1,2 , and $3 \mathrm{~h}$ ) is characterized by an increased production and release of prostaglandins (PGs), as well as reactive species of oxygen from migratory neutrophils $[19,20]$. Considering this fact, our next experiment aimed to investigate the activity of MPO, an enzyme released essentially by activated neutrophils, in the model of 

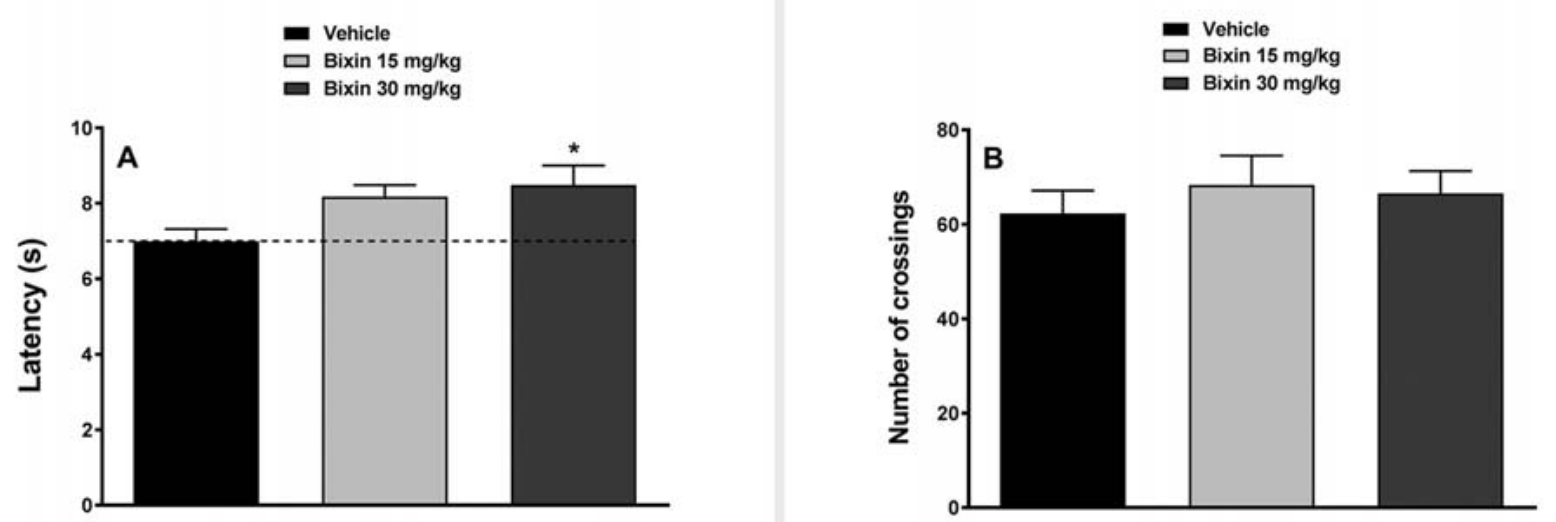

- Fig. 6 Effect of bixin in hot plate latency (panel A) and on number of crossings during the open field test (panel B) in rats. Vehicle (corn oil; $1 \mathrm{~mL}$ $\mathrm{kg}$, p. o.) or bixin ( 15 or $30 \mathrm{mg} / \mathrm{kg}$, p. o.) was administered $1 \mathrm{~h}$ before the behavioral tests. The data represent mean + SEM (panel A, $n=13-14 ;$ panel $\mathrm{B}, \mathrm{n}=6-7) .{ }^{*} \mathrm{p}<0.05$ compared to the vehicle-treated group.

carrageenan-induced inflammation. It was observed that bixin treatment significantly decreased the MPO activity in carrageenan-inflamed skin samples, suggestive of a lower infiltration of leukocytes to the injured tissue. Although not investigated in our study, previous work has already shown that bixin significantly decreases the levels of inflammatory markers such as interleukin 6 and tumor necrosis factor alpha [21] and reduces the in vitro activity of both cyclooxygenase isoforms activity, reducing the levels of PGs [17]. This anti-inflammatory effect of bixin has been also associated to its agonist action on peroxisome proliferator-activated receptor (PPAR) alpha and PPAR gamma, which, among other actions, promote the reduction of inflammatory cytokines and inhibition of macrophage activation [18]. Finally, it has been described some cytoprotective effects of bixin due to its activation of the transcription factor NRF2 (nuclear factor-E2-related factor 2) [22], which regulates the expression of numerous antioxidants, anti-inflammatory, and pro-survival genes [15, 17, 22].

Since pain is one of the cardinal signs of inflammation, our next experiments were designed to characterize an antinociceptive potential of bixin, an effect still unheard of in the literature. We first start testing the effect of bixin on the nociceptive responses induced by formalin. The formalin test is characterized by 2 distinct phases of nociceptive behavior [23]. The first phase, called neurogenic, begins shortly after the formalin injection, remaining until $3 / 5 \mathrm{~min}$, and occurs due to chemical stimulation of the nociceptors by formaldehyde [24]. After occurs a quiescent period (6$15 \mathrm{~min}$ ), and then the second phase (15-60 min) begins. This second phase, called inflammatory, is characterized by the return of nociceptive behaviors and the involvement of peripheral inflammatory mediators, which sensitize primary and spinal sensory neurons, triggering the activation of nociceptors [24]. The different properties of both phases allow this test to be widely used as a tool to indicate possible mechanisms of action for drugs being tested in regards a peripheral and/or a central mechanism of action [25]. In our study, bixin treatment (at both tested doses) induces a significant decrease of formalin-induced flinches during phases I and II of the formalin test, but not during the quiescent interphase, corroborating its anti-inflammatory activity and suggesting that bixin exerts its antinociceptive effect acting peripherally and centrally.

To confirm this, we also test the effect of bixin on the acetic acid-induced writhing in mice. It has been well described that the i. p. administration of acetic acid induces hyperalgesia by promoting the release of noxious endogenous substances, such as cytokines, PGs, substance $P$, and bradykinin, which are responsible for sensitization of nociceptors' nerve endings [26,27]. After injurious stimulation, large amounts of various PGs are produced by polymorphonuclear cells, especially neutrophils, enhancing biosynthesis and release thereof into the peritoneal cavity $[28,29]$. As mentioned, to our knowledge there are no studies involving nociception using isolated bixin. However, Shilpi et al. [9] have also observed a decrease in the number of acetic acid-induced abdominal writhes after the treatment with the foliar methanolic extract of $B$. orellana. Drugs with anti-inflammatory and antioxidant properties have been described as being effective in decreasing nociceptive behaviors and PGs levels in the peritoneal cavity in this nociception test. Although not thoroughly investigated in the present study, the antinociceptive effect of bixin observed in this test is possibly due to its anti-inflammatory and antioxidant properties [28], its capacity to negatively modulate PG production by cyclooxygenase (COX) inhibition [17,30], and its ability to reduce neutrophil migration (the reduction of MPO activity). In contrast to previous findings, in this test, the effect of bixin was not dose-related (i.e., the lower dose of bixin significantly reduced the total number of writhes performed during the 30 min when compared to the higher dose). This fact may be attributed to physiological and interspecific differences between the rats and mice since the acetic acid-induced abdominal writhing test was the only one conducted in Swiss albino mice in this study. Corroborating this hypothesis, the previous study from Pinzon-Garcia et al. [31] has also not observed a dose-response effect of bixin treatment on wound healing using Swiss mice as an animal model.

To confirm that the antinociceptive effect of bixin involves central nervous system (CNS)-mediated mechanisms, in our next ex- 
periment, the effect of bixin was investigated on the latency to noxious thermal stimulus in the hot plate test. It has been well characterized that drugs that act exclusively by their peripheral actions, such as COX inhibitors, do not significantly alter the behavioral responses in this test, making this a widely used model to evaluate drugs with potential action on the CNS [32]. Bixin treatment significantly increased the latency to the noxious thermal stimulus in the hot plate, demonstrating that central mechanisms may contribute to the antinociceptive effect exerted by bixin (at least at the higher dose). Especially because of this possible effect on CNS and in studies involving nociceptive behaviors that depend on the display of active motor behaviors, it is extremely important to rule out the possibility that compounds have sedative effects. To elucidate whether the treatment with bixin promotes any locomotor deficit, the open field test was performed. As shown, the treatment with bixin (at both tested dose) did not alter the number of crossings in the open field test, excluding the sedative effect as a contributor to the antinociceptive responses observed in the formalin and hot plate tests. Curiously, Shilpi et al. [9] reported that the methanolic extract of the leaves of $B$. orellana promoted a decrease in locomotion in this behavioral test, which was not observed using the isolated bixin.

In this study, we demonstrated the anti-inflammatory property of bixin. It seems to be due to its capacity of bixin to reduce the neutrophil migration to the inflammatory site. Furthermore, this is the first report showing the antinociceptive property of bixin, which does not appear to be related to the sedative effect but is associated with both peripheral and central actions. Further studies are necessary to characterize the mechanisms involved in these effects.

The ${ }^{1} \mathrm{H}$ and ${ }^{13} \mathrm{C}$ NMR spectra and the absorption at the maximum lambda in the UV region of bixin are available as Supporting Information.

\section{Material and Methods}

\section{Plant material}

B. orellana (annatto) seeds were collected at the Instituto Ambiental do Paraná (IAP) in Morretes, Paraná, Brazil, in June and July

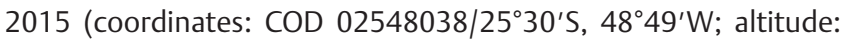
$59 \mathrm{~m}$ ). The plant material was identified by Osmar dos Santos Ribas from Municipal Botanical Museum of Curitiba, where a voucher specimen (\#379.394) was deposited. Permission to evaluate the bioactivities of the extracts from Brazilian plants was granted by the Instituto Brasileiro do Meio Ambiente e dos Recursos Naturais Renováveis (\# 02001.001165/2013-47).

\section{Isolation of bixin}

The seeds $(1000 \mathrm{~g} \pm 0.1)$ were dried at $50^{\circ} \mathrm{C}$, pulverized, and passed through a 35-mesh sieve. The powdered material was extracted in a modified Soxhlet apparatus using increasing polarity solvents $(1: 10 ; \mathrm{w} / \mathrm{v})$ (hexane, chloroform, ethyl acetate, and ethanol) for $6 \mathrm{~h}$ and subsequently filtered through Whatman No. 41 filter paper. The red-purple powder of bixin (yield: $5.1 \%$ ) was obtained by extracting chloroform with hexane from the previously defatted seeds $[14,33]$. The polarity gradient was performed to certify that bixin would not be present in other solvents such as ethyl acetate and ethanol. The material was oven-dried and stored at $-16^{\circ} \mathrm{C}$. The measured melting point of bixin $\left(195^{\circ} \mathrm{C}\right)$ was similar to previously described in the literature $[3,14,34]$.

\section{Bixin identification}

The bixin identification was supported by nuclear magnetic resonance spectroscopy (NMR; $1 \mathrm{H}$ and 13C; Fig. 1S and Fig. 2S, Supporting Information) as well as by UV (Fig. 3S, Supporting Information) and IR $[3,35]$. The purity of bixin was estimated to be greater than 99\%. In agreement with the literature [3,36,37], our results showed UV $\lambda$, nm: 489, 462, 432,7. IR $\mathrm{v}(\mathrm{KBr}) \mathrm{cm}$ 11716.64, 1660, 1614, 1385, 1300, and 900. 1H NMR $(600 \mathrm{M}$ Hz. DMSO-d6), $\delta 7.89(1 \mathrm{H}, \mathrm{d}, \mathrm{J}=15.5 \mathrm{~Hz}, \mathrm{H}-7), \delta 7.26(1 \mathrm{H}, \mathrm{d}$, $\left.\mathrm{J}=15.5 \mathrm{~Hz}, \mathrm{H}-7^{\prime}\right), 6.45-6.87(10 \mathrm{H}, \mathrm{m}, 10 \mathrm{x}: \mathrm{CH}), 5.83(1 \mathrm{H}, \mathrm{d}$, $\mathrm{J}=15.5 \mathrm{~Hz}, \mathrm{H}-8), 5.94\left(1 \mathrm{H}, \mathrm{d}, \mathrm{J}=15.5 \mathrm{~Hz}, \mathrm{H}-8^{\prime}\right), 3.70(3 \mathrm{H}, \mathrm{s}$, OMe), 1.92-1.99 (12 H, m, 4 x: CMe).

\section{In vivo experiments}

\section{Animals}

Adult male Wistar rats (180-220 g) and Swiss albino mice (18$35 \mathrm{~g}$ ), supplied by the Federal University of Parana colony, were used in this study. Animals were housed in plastic cages $(41 \times 32 \times 16.5 \mathrm{~cm})$ and maintained in standard conditions of room temperature $\left(21 \pm 2^{\circ} \mathrm{C}\right)$ and illumination cycle (12-h light/ dark) with food and water provided ad libitum. Bixin (15 or $30 \mathrm{mg} / \mathrm{kg}$ in rats; 27 or $53 \mathrm{mg} / \mathrm{kg}$ in mice, calculated according to its basal metabolic rate, using the method proposed by Freitas and Carregaro [38]) or vehicle (1 mL/kg; corn oil) was administered orally by gavage after 12 -h fasting. Animals were habituated to the experimental room for at least $1 \mathrm{~h}$ before the experiments. The study was conducted following the National Institutes of Health Guide for the Care and Use of Laboratory Animals and approved by the Federal University of Parana Institutional Committee on the Ethical Use of Animals (CEUA/BIO-UFPR; authorization \#1087, approved on August 15, 2017). All efforts were made to minimize the number of animals, following the reduction principle recommended by Russell and Burch [39]. For this reason, pharmacological positive control groups were not conducted for behavioral experiments related to the potential antinociceptive effect of bixin since the antinociceptive effect of drugs such as non steroidal anti-inflammatory drugs (NSAIDs) or opioids has been extensively observed using the same animal models [40,41].

Carrageenan-induced paw edema and measurement of the MPO activity

To evaluate the potential anti-inflammatory effect of bixin, the paw edema was induced by intra-plantar injection of carrageenan (Cg; Sigma-Aldrich; purity: approximately $52 \%$ ), at the dose of $200 \mu \mathrm{g} /$ paw in $0.1 \mathrm{~mL}$ of saline, according to previously described by Hirota et al. [42]. Briefly, 4 experimental groups were designed ( $n=8$ rats/each): negative control group orally (p. o.) treated with corn oil (bixin vehicle; equivalent volume); bixin-treated groups (15 or $30 \mathrm{mg} / \mathrm{kg}$; p.o.); and positive control treated with dexamethasone $(1 \mathrm{mg} / \mathrm{kg}$, subcutaneous injection). All treatments were administered $1 \mathrm{~h}$ before the injection of carrageenan. Bixin doses were selected based on previous studies $[4,13,14]$. As a 
control, contralateral paws received saline ( $\mathrm{Cg}$ vehicle; $0.1 \mathrm{~mL})$. The paw thickness was evaluated before (basal measurement) and again $1,2,3$, and $4 \mathrm{~h}$ after $\mathrm{Cg}$ or saline $(0.1 \mathrm{~mL} / \mathrm{paw})$ injections, using a digital pachymeter and expressed in millimeters (mm).

In another set of experiments, all the above experimental groups and procedures were repeated. However, $3 \mathrm{~h}$ after $\mathrm{Cg}$ (peak of edema) or saline injections, rats were euthanized and segments of the sub-plantar region of both hind paws were collected, weighed and stored at $-80^{\circ} \mathrm{C}$. The MPO activity was determined according to the methodology described by De Young et al. [43] with modifications. In brief, tissue samples were homogenized in $1.5 \mathrm{~mL}$ of sodium phosphate buffer $(80 \mathrm{nM}, 0.5 \%$ hexadacyl trimethylammonium bromide [HTAB], $\mathrm{pH} 5.4$ ) for $15 \mathrm{~s}$ at $0{ }^{\circ} \mathrm{C}$. The homogenate was then centrifuged at $11,200 \mathrm{~g}$ at $4{ }^{\circ} \mathrm{C}$ for $20 \mathrm{~min}$. Then triplicates of $30 \mu \mathrm{L}$ supernatant were transferred to plates, which previously received $200 \mu \mathrm{L}$ of peroxide solution $(100 \mu \mathrm{L}$ of $80 \mathrm{mM}$ sodium phosphate buffer, $85 \mu \mathrm{L}$ of $0.22 \mathrm{mM}$ sodium phosphate buffer plus $15 \mu \mathrm{L}$ of hydrogen peroxide $0.017 \%$ ). The reaction was started with the addition of $20 \mu \mathrm{L}$ of TMB solution (18.4 nM dissolved in $8 \%$ aqueous dimethylformamide). The plate was then transferred to the greenhouse for 3 min at $37^{\circ} \mathrm{C}$ and thereafter the reaction was stopped by the addition of $30 \mu \mathrm{L}$ of sodium acetate $(1.46 \mathrm{M})$ in each well. The enzymatic activity was evaluated by the colorimetric method using a plate reader (Bio-Tek Ultra Microplate reader EL808), with a wavelength of $620 \mathrm{~nm}$. The results were expressed as optical density (OD)/total sample weight.

\section{Formalin test}

The potential antinociceptive effect of bixin was firstly evaluated in the formalin test according to Hirota et al. [42] with modifications. Briefly, 50 min after oral treatment with vehicle (corn oil; $1 \mathrm{~mL} / \mathrm{kg}$ ) or bixin (15 or $30 \mathrm{mg} / \mathrm{kg}$ ), rats ( $\mathrm{n}=7-9$ each group) were acclimated in the formalin test apparatus (an inverted glass funnels $290 \mathrm{~mm}$ wide and $410 \mathrm{~mm}$ high) for $10 \mathrm{~min}$. Then animals received the formalin injection $(2.5 \%, 50 \mu \mathrm{L} / \mathrm{rat})$ into the dorsal surface of one of the hind paws. Flinches were scored immediately after formalin injection for $60 \mathrm{~min}$, divided into 5 -min periods with the phases defined as the following time intervals: phase I (0-5 min), quiescent phase (6-15 min), and phase II (16$60 \mathrm{~min})$. Results were expressed as the cumulative number of flinches during the 60 min of the test and the sum of total flinches at each phase of the test.

\section{Acetic acid-induced writhing test}

The writhing test was performed following the procedures previously described by Hirota et al. [42]. For this, 50 min after oral treatment with vehicle (corn oil; equivalent volume; p. o.) or bixin ( 27 or $53 \mathrm{mg} / \mathrm{kg}$; p.o.), mice ( $\mathrm{n}=10-11$ each group) were placed to acclimate in an inverted glass funnel $(290 \mathrm{~mm}$ wide and $410 \mathrm{~mm}$ high) for $10 \mathrm{~min}$. The doses of bixin used in mice were calculated according to the general method of calculation for the allometric scale of drugs, based on the basal metabolic rate of the animals [32]. One hour after the vehicle or bixin treatment, each mouse was injected with acetic acid $0.6 \%(10 \mathrm{~mL} / \mathrm{kg}$; i. p. injection) and individually housed in the glass cylinder. The cumulative number of writhes (characterized by abdominal constriction and stretching of at least 1 hind limb) was scored for 30 min.

\section{Hot plate test}

The potential antinociceptive effect of bixin over an acute thermal stimulus $\left(50 \pm 1^{\circ} \mathrm{C}\right)$ was evaluated using a hot plate apparatus (Ugo Basile SRL), as previously described [44]. For this, rats ( $n=6-7$ each group) were divided into 3 different groups treated with vehicle (corn oil; $1 \mathrm{~mL} / \mathrm{kg}$; p.o.) or bixin (15 or $30 \mathrm{mg} / \mathrm{kg}$; p.o.). The latency (in seconds) for animals to display behaviors such as licking of the fore and hind paws or jumping was measured before and $1 \mathrm{~h}$ after corn oil or bixin treatments. The cutoff time used to prevent skin damage was $25 \mathrm{~s}$.

\section{Open field test}

The open field test was conducted to evaluate the effect of treatments over the spontaneous locomotor activity, according to Meotti et al. [45]. Briefly, $1 \mathrm{~h}$ after treatment with vehicle (corn oil; $1 \mathrm{~mL} / \mathrm{kg}$, p. o.) or bixin (15 or $30 \mathrm{mg} / \mathrm{kg}$, p.o.) rats $(\mathrm{n}=6-7$ each group) were placed in the center of the open field apparatus (a rectangular wooden arena; $40 \mathrm{~cm}$ wide $\times 50 \mathrm{~cm}$ long $\times 63 \mathrm{~cm}$ high; divided into 9 rectangular units). The locomotor activity was video recorded, and the number of units crossed with all 4 paws was counted for 5 min.

\section{Statistical analysis}

The data were presented by the mean plus standard error of the mean (SEM) for 6 to 14 animals per group. Data were compared using 2-way ANOVA with repeated measures (time-course behavioral data, where the independent factors used were treatment and time) or 1-way ANOVA (column graphs). When appropriate, the post hoc analysis of Bonferroni was applied. The level of significance was established at $p<0.05$. All the tests were carried out using the GraphPad Prism program (version 6).

\section{Supporting Information}

The ${ }^{1} \mathrm{H}$ and ${ }^{13} \mathrm{C}$ NMR spectra and the absorption at the maximum lambda in the UV region of bixin are available as Supporting Information.

\section{Acknowledgements}

SDG Pacheco, AT Gasparin, CHA Jesus, ACSSB Ventura, and DDB Redivo are recipients of Coordenação de Aperfeiçoamento de Pessoal de Nível Superior (CAPES) fellowships (Finance Code 001). The authors are grateful to CNPq and UFPR for institutional financial support.

\section{Conflict of Interest}

The authors declare that they have no conflict of interest.

\section{References}

[1] Vilar DA, Vilar MSA, Moura TFAL, Raffin FN, Oliveira MR, Franco CFO, Athayde-Filho PF, Diniz MFFM Barbosa-Filho JM. Traditional uses, chemical constituents, and biological activities of Bixa orellana L.: a review. ScientificWorldJournal 2014; 2014: 857292. doi:10.1155/2014/857292 
[2] Silva CR, Antunes LM, Bianchi ML. Antioxidant action of bixin against cisplatin-induced chromosome aberrations and lipid peroxidation in rats. Pharmacol Res 2001; 43: 561-566

[3] Jondiko IJO, Pattenden G. Terpenoids and an apocarotenoid from seeds of Bixa orellana. Phytochemistry 1989; 28: 3159-3162

[4] Tao S, Park SL, Vega D, Zhang DD, Wondrak GT. Free radical biology and medicine systemic administration of the apocarotenoid bixin protects skin against solar UV-induced damage through activation of NRF2. Free Radic Biol Med 2015; 89: 690-700

[5] Chengaiah B, Rao KM, Kumar KM, Alagusundaram M, Chetty CM. Medicinal importance of natural dyes - a review. Int J PharmTech Res 2010; 2: 144-154

[6] Ulbricht C, Windsor RC, Brigham A, Bryan JK, Conquer J, Costa D, Giese N, Guilford J, Higdon ERB, Holmes K, Isaac R, Jingst S, Kats J, Peery L, Rusie E, Savinainen A, Schoen T, Stock T, Tanguay-Colucci S, Weissner W. An Evidence-based systematic review of annatto (Bixa orellana L.) by the Natural Standard Research Collaboration. J Diet Suppl 2012; 9: 5777

[7] Benoit PS, Fong HH, Svoboda GH, Farmsworth NR. Biological and phytochemical evaluation of plants. XIV. Antiinflammatory evaluation of 163 species of plants. Lloydia 1976; 39: 160-171

[8] Yoke Keong Y, Arifah AK, Sukardi S, Roslida AH, Somchit MN, Zuraini A. Bixa orellana leaves extract inhibits bradykinin-induced inflammation through suppression of nitric oxide production. Med Princ Pract 2011; 20: $142-146$

[9] Shilpi JA, Taufiq-Ur-Rahman M, Uddin SJ, Alam MS, Sadhu SK, Seidel V. Preliminary pharmacological screening of Bixa orellana L. leaves. J Ethnopharmacol 2006; 108: 264-271

[10] Hernández-Ortega M, Ortiz-Moreno A, Hernández-Navarro MD, Chamorro-Cevallos G, Dorantes-Alvarez L, Necoechea-Mondragón H. Antioxidant, antinociceptive, and anti-inflammatory effects of carotenoids extracted from dried pepper (Capsicum annuum L.). J Biomed Biotechnol 2012; 2012: 524019

[11] Boiko YA, Kravchenko IA, Shandra AA, Boiko IA. Extraction, identification and anti-inflammatory activity of carotenoids out of Capsicum Anuum L. J HerbMed Pharmacol 2017; 6: 10-15

[12] Xu Z, Kong XQ. Bixin ameliorates high fat diet-induced cardiac injury in mice through inflammation and oxidative stress suppression. Biomed Pharmacother 2017; 89: 991-1004

[13] Tao S, Rojo de la Vega M, Quijada H, Wondrak GT, Wang T, Garcia JG, Zhang DD. Bixin protects mice against ventilation-induced lung injury in an NRF2-dependent manner. Sci Rep 2016; 6: 18760. doi:10.1038/ srep 18760

[14] Pinzón-García AD, Cassini-Vieira P, Ribeiro CC, de Matos Jensen CE, Barcelos LS, Cortes ME, Sinisterra RD. Efficient cutaneous wound healing using bixin-loaded PCL nanofibers in diabetic mice. J Biomed Mater Res B Appl Biomater 2017; 105: 1938-1949

[15] Levy LW, Regalado E, Navarrete S, Watkins RH. Bixin and norbixin in human plasma: determination and study of the absorption of a single dose of annatto food color. Analyst 1997; 122: 977-980

[16] Food WHO. Safety evaluation of certain food additives and contaminants. Available at http://www.inchem.org/documents/jecfa/jecmono/ v52je03.htm\#abs. Accessed August 12, 2019

[17] Reddy MK, Alexander-Lindo RL, Nair MG. Relative inhibition of lipid peroxidation, cyclooxygenase enzymes, and human tumor cell proliferation by natural food colors. J Agric Food Chem 2005; 53: 9268-9273

[18] Takahashi N, Goto T, Taimatsu A, Egawa K, Katoh S, Kusudo T, Sakamoto T, Ohyane C, Lee JY, Kim YI, Uemura T, Hirai S, Kawada T. Bixin regulates mRNA expression involved in adipogenesis and enhances insulin sensitivity in 3T3-L1 adipocytes through PPARy activation. Biochem Biophys Res Commun 2009; 390: 1372-1376
[19] Di Rosa M, Giroud JP, Willoughby DA. Studies of the mediators of the acute inflammatory response induced in rats in different sites by carrageenan and turpentine. J Pathol 1971; 104: 15-29

[20] Vinegar R, Schreiber W, Hugo R. Biphasic development of carrageenan edema in rats. J Pharmacol Exp Ther 1968; 166: 96-103

[21] Somacal S, Figueiredo CG, Quatrin A, Ruviaro AR, Conte L, Augusti PR, Roehrs M, Denardin IT, Kasten J, da Veiga ML, Duarte MMF, Emanuelli T. The antiatherogenic effect of bixin in hypercholesterolemic rabbits is associated to the improvement of lipid profile and to its antioxidant and anti-inflammatory effects. Mol Cell Biochem 2015; 403: 243-253

[22] Tao S, Park SL, Rojo de la Vega M, Zhang DD, Wondrak GT. Systemic administration of the apocarotenoid bixin protects skin against solar UVinduced damage through activation of NRF2. Free Radic Biol Med 2015; 89: $690-700$

[23] Tjølsen A, Berge OG, Hunskaar S, Rosland JH, Hole K. The formalin test: an evaluation of the method. Pain 1992; 51: 5-17

[24] Dubuisson D, Dennis SG. The formalin test: a quantitative study of the analgesic effects of morphine, meperidine, and brain stem stimulation in rats and cats. Pain 1977; 4: 161-174

[25] Malmberg AB, Yaksh TL. Antinociceptive actions of spinal nonsteroidal anti-inflammatory agents on the formalin test in the rat. J Pharmacol Exp Ther 1992; 263: 136-146

[26] Berkenkopf JW, Weichman BM. Production of prostacyclin in mice following intraperitoneal injection of acetic acid, phenylbenzoquinone and zymosan: its role in the writhing response. Prostaglandins 1988; 36 : 693-709

[27] Ribeiro RA, Vale ML, Thomazzi SM, Paschoalato ABP, Poole S, Ferreira SH, Cunha FQ. Involvement of resident macrophages and mast cells in the writhing nociceptive response induced by zymosan and acetic acid in mice. Eur J Pharmacol 2000; 3: 111-118

[28] Deraedt R, Jouquey S, Delevallée F, Flahaut M. Release of prostaglandins $E$ and $F$ in an algogenic reaction and its inhibition. Eur ] Pharmacol 1980; 61: 17-24

[29] Tolone G. Prostaglandin production by human polymorphonuclear leucocytes during phagocytosis in vitro. Experientia 1977; 519: 961-962

[30] Russell EA, Lynch PB, O’Sullivan K, Kerry JP. Dietary supplementation of alpha-tocopheryl acetate on alpha-tocopherol levels in duck tissues and its influence on meat storage stability. Int J Food Sci Technol 2004; 39: $331-340$

[31] Pinzón-García AD, Cassini-Vieira P, Ribeiro CC, Eduardo C, Jensen DM, Barcelos LS, Cortes ME, Sinisterra RD. Efficient cutaneous wound healing using bixin-loaded PCL nanofibers in diabetic mice. J Biomed Mater Res B Appl Biomater 2016; 105: 1-12

[32] Ballou LR, Botting RM, Goorha S, Zhang J, Vane JR. Nociception in cyclooxygenase isozyme-deficient mice. Proc Natl Acad Sci 2000; 97: 10272 10276

[33] Petenate AJ, Rodrigues LM, Alca SC, Meireles MAA. Bixin extraction from defatted annatto seeds. Comptes Rendus Chimie 2014; 17: 268-283

[34] Golin SD, Garcia CER, Barreira SMW, Bednarczuk VO, Strapasson GC, Zuchetto M, Miguel OG. Teor de bixina em duas variedades de Bixa orellana L. cultivadas no Paraná. Visão acadêmica 2013; 14: 37-48

[35] Rehbein J, Dietrich B, Grynbaum MD, Hentschel P, Holtin K, Kuehnle M, Schuler P, Bayer M, Albert K. Characterization of bixin by LC-MS and LC-NMR. J Sep Sci 2007; 30: 2382-2390

[36] Noppe H, Abuín Martinez S, Verheyden K, Van Loco J, Companyó Beltran $\mathrm{R}$, De Brabander HF. Determination of bixin and norbixin in meat using liquid chromatography and photodiode array detection. Food Addit Contam Part A Chem Anal Control Expo Risk Assess 2009; 26: 17-24

[37] Scotter M], Thorpe SA, Reynolds SL, Wilson LA, Strutt PR. Characterization of the principal colouring components of annatto using high performance liquid chromatography with photodiode-array detection. Food Addit Contam 1994; 11: 301-315 
[38] Freitas GC, Carregaro AB. Aplicabilidade da extrapolação alométrica em protocolos terapêuticos para animais selvagens. Ciência Rural 2013; 43 : 297-304

[39] Tannenbaum J, Bennett BT. Russell and Burch's 3Rs then and now: the need for clarity in definition and purpose. J Am Assoc Lab Anim Sci 2015; 54: 120-132

[40] Venâncio AM, Onofre AS, Lira AF, Alves PB, Blank AF, Antoniolli AR, Marchioro M, Estevam Cdos S, de Araujo BS. Chemical composition, acute toxicity, and antinociceptive activity of the essential oil of a plant breeding cultivar of basil (Ocimum basilicum L.). Planta Med 2011; 77: 825-829

[41] Dos Santos GC, Gomes GA, Gonçalves GM, de Sousa LM, Santiago GM, de Carvalho MG, Marinho BG. Essential oil from Myrcia ovata: chemical composition, antinociceptive and anti-inflammatory properties in mice. Planta Med 2014; 80: 1588-1596

[42] Hirota BCK, Paula CDS, De Oliveira VB, Da Cunha JM, Schreiber AK, Ocampos FMM, Barison A, Miguel OG, Miguel MD. Phytochemical and antinociceptive, anti-inflammatory, and antioxidant studies of smilax larvata (Smilacaceae). Evid Based Complement Alternat Med 2016; 2016: 9894610

[43] De Young LM, Kheifets JB, Ballaron S], Young JM. Edema and cell infiltration in the phorbol ester-treated mouse ear are temporally separate and can be differentially modulated by pharmacologic agents. Agents Actions 1989; 26: 335-341

[44] Mothana RAA, Al-Said MS, Al-Rehaily AJ, Thabet TM, Awad NA, Lalk M, Lindequist U. Anti-inflammatory, antinociceptive, antipyretic and antioxidant activities and phenolic constituents from Loranthus regularis Steud. ex Sprague. Food Chem 2012; 130: 344-349

[45] Meotti FC, Luiz AP, Pizzolatti MG, Kassuya CA, Calixto JB, Santos AR. Analysis of the antinociceptive effect of the flavonoid myricitrin: evidence for a Role of the arginine-nitric oxide and protein kinase $C$ pathways. J Pharmacol Exp Ther 2006; 316: 789-796 